\title{
NSAIDs for analgesia in the era of COVID-19
}

\author{
Daniel L Herzberg $\left(\mathbb{0},{ }^{1,2}\right.$ Harry P Sukumaran, ${ }^{1}$ Eugene Viscusi ${ }^{3}{ }^{3}$
}

${ }^{1}$ Department of Anesthesiology and Pain Medicine, Detroit Medical Center/Wayne State University, Detroit, Michigan, USA

${ }^{2}$ Department of Emergency Medicine, MedStar Georgetown University Hospital, Washington, District of Columbia, USA ${ }^{3}$ Department of Anesthesiology, Sidney Kimmel Medical College at Thomas Jefferson University, Philadelphia, Pennsylvania, USA

Correspondence to Dr Daniel L Herzberg, Department of Anesthesiology and Pain Medicine, Detroit Medical Center/Wayne State University, Detroit, MI 48201, USA; dherzber@dmc.org

Received 18 April 2020 Revised 19 May 2020 Accepted 25 May 2020 Published Online First 3 June 2020

Check for updates

(C) American Society of Regional Anesthesia \& Pain Medicine 2020. No commercial re-use. See rights and permissions. Published by BMJ.

To cite: Herzberg DL, Sukumaran HP, Viscusi E. Reg Anesth Pain Med 2020:45:677-678

\section{ABSTRACT}

Globally, non-steroidal anti-inflammatory drugs

(NSAIDS) are highly used to treat pain. With the rise of the COVID-19 pandemic, the safety of NSAIDs use has been called into question. These concerns are worthy of review. At present, there is no compelling data showing that NSAIDs worsen the severity of COVID-19 symptoms or increase one's likelihood of contracting the illness. For patients in pain and without symptoms that could potentially be attributed to COVID-19 (cough, fevers/ chills, lethargy, myalgias, anosmia and so on), NSAIDs should continue to remain a viable option to provide analgesia to patients in need.

\section{INTRODUCTION}

Globally, non-steroidal anti-inflammatory drugs (NSAIDs) are the most commonly used medications for the treatment of acute and chronic pain. With appropriate patient selection and dosing, these medications have served as a cornerstone of the pharmacologic toolbox to treat pain since the 1800s. ${ }^{1}$ While NSAIDs can provide significant analgesia to patients in pain, this class of medications carries risks including cardiovascular dysfunction, bleeding, gastrointestinal upset and kidney injury. ${ }^{2}$ With the rise of the current coronavirus disease 2019 (COVID-19) global pandemic caused by the spread of the severe acute respiratory syndrome coronavirus 2 (SARS-CoV-2), questions have arisen regarding the safety of NSAIDs during this period of uncertainty on how to best respond to this novel disease. An assessment of the current sources of concern surrounding NSAID use during the pandemic can offer insight on their risk-benefit profile for the treatment of pain at the present time.

\section{DISCUSSION}

The concern regarding NSAID use during the pandemic was first published by three European physicians and scientists in a letter to the editor of the journal The Lancet Respiratory Medicine on 11 March $2020 .^{3}$ While these authors wrote primarily about hypertension and diabetes mellitus as risk factors for contracting COVID19 , they briefly commented that ibuprofen could increase levels of cellularly expressed ACE2. This is potentially concerning as SARS-CoV-2 infects cells by binding to ACE2, which is commonly expressed in tissues of the cardiovascular, gastrointestinal and renal systems. ${ }^{4}$ However, some concerns raised in this letter are observational and have yet to be proven. Furthermore, the authors of this letter do not cite a source for their assertion that ibuprofen can increase levels of ACE2. During our literature search on PubMed for this article, we could not identify research to support this. The uncertainty surrounding the origin of this claim was also examined in an article in Chemical \& Engineering News, a trade magazine published by the American Chemical Society. ${ }^{5}$ They report that the authors of the letter in The Lancet did not offer specific clarification when asked for evidence showing that ibuprofen actually increases ACE2 expression.

More widespread attention regarding NSAID use was garnered by a tweet from the Health Minister of France on 14 March 2020. Oliver Veran advised against using medications like ibuprofen and cortisone and recommended the use of acetaminophen (paracetamol) in patients with COVID-19. There was no specific data referenced to support his recommendation. ${ }^{6}$ His comments appear to have resulted from media reports of four cases of younger patients in France with COVID-19 who took ibuprofen for their symptoms and went on to have worsening symptoms. ${ }^{7}$ No demographic or descriptive information about these patients has been published, and the timing and dosing of ibuprofen in relation to their COVID-19 symptoms are not known.

Following this, several health and governmental groups issued commentary on this subject. The WHO initially recommended that ibuprofen use should be avoided for symptoms of COVID-19. They then reversed that recommendation on 18 March 2020 stating, 'based on currently available information, WHO does not recommend against the use of ibuprofen'. 8 The European Medical Agency, also on 18 March 2020, stated, 'there is currently no scientific evidence establishing a link between ibuprofen and worsening of COVID-19'. 9 This organization did comment that there is evidence that NSAIDs could contribute to a more severe course of chickenpox and some bacterial infections. It also suggested that acetaminophen (paracetamol) was generally the preferred agent for fever and pain during an infectious illness and called for further research on the impact of NSAID use in patients with COVID-19. On 19 March 2020, the US Food and Drug Administration issued a statement that it was 'not aware of scientific evidence connecting the use of NSAIDs, like ibuprofen, with worsening COVID-19 symptoms' ${ }^{10}$ On 19 April 2020, the WHO released a scientific brief to address NSAID use in patients with COVID-19. ${ }^{11}$ While they note the limitation of a current lack of studies directly examining NSAID use in patients with COVID-19, their review included 73 relevant published studies. After examining these studies, the WHO found no evidence to suggest that NSAID use in patients with COVID-19 results in significant adverse events or increased mortality. 
An article examining the impact of NSAID use in patients with COVID-19 noted that while there is evidence that NSAIDs can worsen outcomes in patients with respiratory infections, there is no strong signal yet detected to show this occurs in patients with COVID-19. However, the author notes that there are potential risks associated with using NSAIDs in patients without infection including heart attacks, stroke and kidney injury. The author suggests these risks could be increased if fever and dehydration occur due to an infection like COVID-19. Given the potential risks, the author concluded that NSAIDs should likely not be first-line treatment for fever and pain in patients with COVID19. ${ }^{12}$ However, a recent review article that also examines potential connections between NSAIDs and COVID-19 noted that studies examining ibuprofen's connection with the outcomes of respiratory illnesses are often at risk of different types of biases. ${ }^{13}$ Potential biases include the risk of assuming a causality between ibuprofen administration and a disease's natural course of severity when they may not be related (protopathic bias) and also the risk of selection bias where NSAIDs may not be used unless more severe symptoms are present. Additionally, many patients who take NSAIDs chronically for pain have other chronic medical conditions that can increase their risk profile for poorer COVID-19 outcomes compared with otherwise healthy patients-making attempts to correlate NSAID use with respiratory illness outcomes a challenging endeavor. It should be noted that many studies examining NSAIDs and respiratory infection outcomes focus on bacterial rather than viral illnesses. One retrospective study from 2016 examined NSAID use in H1N1 influenza patients and found 'no compelling evidence' that NSAID use increased mortality in these patients. ${ }^{14}$ Interestingly, a recent prospective trial of hospitalized patients with influenza found that the use of naproxen, in conjunction with other medications, actually yielded a mortality benefit. ${ }^{15}$

\section{CONCLUSION}

While an absence of evidence regarding NSAIDs interplay with the manifestation of COVID-19 symptoms and subsequent severity of illness does not necessarily equate to evidence of absence, the current state of the data surrounding this claim must be considered when currently treating patients. At present, we cannot locate any data showing that ibuprofen worsens the severity of COVID-19 symptoms or increases one's likelihood of contracting the illness. Similarly, in a recent article by a fellow pain medicine physician in Italy, no link between NSAIDs and COVID-19 could be found in the published literature. ${ }^{16}$ Furthermore, the present concerns that have been raised regarding NSAIDs have been specific for their use in patients with COVID-19 symptoms, not asymptomatic patients who otherwise have pain that needs to be treated.

At this time, there is no reason to remove NSAIDs as an option for treating appropriate patients in pain, especially if they are without possible or confirmed COVID-19 symptoms. The presence of a pandemic does not alter the baseline risks of NSAIDs use, which should be avoided or used with caution in several situations including when treating patients who have renal or cardiovascular disease or advanced age. That said, no pharmacologic treatment for pain is without risks, and other options have been associated with worsening immune function. For example, the role of opioids functioning as an immunosuppressant have been well documented. ${ }^{17-19}$ Thus, it appears reasonable for patients who take NSAIDs chronically to continue to do so and to continue to use this class of medication judiciously to treat acute pain as well. However, until more data arises, it would be reasonable, out of an abundance of caution, to avoid NSAID use in patients who have possible symptoms of, or recent high-risk exposures to, COVID-19.

Contributors All authors played a substantial role in the creation of this article.

Funding The authors have not declared a specific grant for this research from any funding agency in the public, commercial or not-for-profit sectors.

Competing interests None declared.

Patient consent for publication Not required.

Provenance and peer review Commissioned; externally peer reviewed.

This article is made freely available for use in accordance with BMJ's website terms and conditions for the duration of the covid-19 pandemic or until otherwise determined by BMJ. You may use, download and print the article for any lawful, non-commercial purpose (including text and data mining) provided that all copyright notices and trade marks are retained.

\section{ORCID iDs}

Daniel L Herzberg http://orcid.org/0000-0001-7718-0052

Eugene Viscusi http://orcid.org/0000-0003-0260-4396

\section{REFERENCES}

1 Rao P, Knaus EE. Evolution of nonsteroidal anti-inflammatory drugs (NSAIDs): cyclooxygenase (COX) inhibition and beyond. J Pharm Pharm Sci 2008;11:81-110.

2 Barkin RL, Beckerman M, Blum SL, et al. Should nonsteroidal anti-inflammatory drugs (NSAIDs) be prescribed to the older adult? Drugs Aging 2010;27:775-89.

3 Fang L, Karakiulakis G, Roth M. Are patients with hypertension and diabetes mellitus at increased risk for COVID-19 infection? Lancet Respir Med 2020;8:e21.

4 Wan Y, Shang J, Graham R, et al. Receptor recognition by the novel coronavirus from Wuhan: an analysis based on decade-long structural studies of SARS coronavirus. J Virol 2020;94.

5 Krietsch Boerner L. No evidence to support link between ibuprofen and COVID-19, experts say. Chemical \& Engineering News, 2020. Available: https://cen.acs.org/ pharmaceuticals/evidence-support-link-between-ibuprofen/98/web/2020/03

$6 @$ @olivierveran. La prise d'anti-inflammatoires (ibuprofène, cortisone) pourrait être un facteur d'aggravation de l'infection. En cas de fièvre, prenez du paracétamol. Si vous êtes déj sous anti-inflammatoires ou en cas de doute, demandez conseil votre médecin." Twitter, 2020. Available: https://twitter.com/olivierveran/status/ 1238776545398923264

7 Day M. Covid-19: European drugs agency to review safety of ibuprofen. BMJ 2020;368:m1168.

8 ScienceAlert. Updated: WHO now doesn't recommend avoiding ibuprofen for COVID-19 symptoms, 2020. Available: https://www.sciencealert.com/whorecommends-to-avoid-taking-ibuprofen-for-covid-19-symptoms

9 European Medicines Agency. Ema gives advice on the use of non-steroidal antiinflammatories for COVID-19, 2020. Available: https://www.ema.europa.eu/en/news/ ema-gives-advice-use-non-steroidal-anti-inflammatories-covid-19

10 Food and Drug Administration. Fda advises patients on use of non-steroidal antiinflammatory drugs (NSAIDs) for COVID-19, 2020. Available: https://www.fda. gov/drugs/drug-safety-and-availability/fda-advises-patients-use-non-steroidal-antiinflammatory-drugs-nsaids-covid-19

11 World Health Organization. The use of non-steroidal anti-inflammatory drugs (NSAIDs) in patients with COVID-19, 2020. Available: https://www.who.int/newsroom/commentaries/detail/the-use-of-non-steroidal-anti-inflammatory-drugs-(nsaids)in-patients-with-covid-19

12 Little P. Non-Steroidal anti-inflammatory drugs and covid-19. BMJ 2020;368:m1185 https://www.bmj.com/content/368/bmj.m1185.long

13 Sodhi M, Etminan M. Safety of ibuprofen in patients with COVID-19; causal or confounded? Chest 2020:pii: S0012-3692(20)30572-9.

14 Epperly H, Vaughn FL, Mosholder AD, et al. Nonsteroidal anti-inflammatory drug and aspirin use, and mortality among critically ill pandemic H1N1 influenza patients: an exploratory analysis. Jpn J Infect Dis 2016;69:248-51.

15 Hung IFN, To KKW, Chan JFW, et al. Efficacy of Clarithromycin-NaproxenOseltamivir Combination in the Treatment of Patients Hospitalized for Influenza A(H3N2) Infection: An Open-label Randomized, Controlled, Phase IIb/III Trial. Chest 2017; 151:1069-80.

16 Varrassi G. Warning against the use of anti-inflammatory medicines to cure COVID-19: building Castles in the air. Adv Ther 2020;37:1705-7.

17 Pacifici R, Patrini G, Venier I, et al. Effect of morphine and methadone acute treatment on immunological activity in mice: pharmacokinetic and pharmacodynamic correlates. J Pharmacol Exp Ther 1994;269:1112-6.

18 Roy S, Loh HH. Effects of opioids on the immune system. Neurochem Res 1996;21:1375-86

19 Chang M-C, Fan S-Z, Hsiao P-N, et al. Influence of morphine on host immunity. Acta Anaesthesiol Taiwan 2011:49:105-8. 